\title{
Acute Impact of Artificial Sweetener, Aspartame on Blood Parameter in Mice
}

\author{
Ayoub A. Bazzaz ${ }^{*}$, Norah S. Al-Johani² \\ ${ }^{1}$ Department of Basic Science, Faculty of Dentistry, University of Kerkuk, Kerkuk, Iraq \\ ${ }^{2}$ Department of Biology, Ladies Section, Faculty of Science, University of Taibah, Al-Madina Al-Munawara, KSA \\ Email: ^ayoubbazzaz@yahoo.co.uk
}

How to cite this paper: Bazzaz, A.A. and Al-Johani, N.S. (2018) Acute Impact of Artificial Sweetener, Aspartame on Blood Parameter in Mice. Advances in Bioscience and Biotechnology, 9, 549-560. https://doi.org/10.4236/abb.2018.910038

Received: September 19, 2018

Accepted: October 28, 2018

Published: October 31, 2018

Copyright (c) 2018 by authors and Scientific Research Publishing Inc. This work is licensed under the Creative Commons Attribution International License (CC BY 4.0).

http://creativecommons.org/licenses/by/4.0/

(c) (i) Open Access

\begin{abstract}
Aspartame (APM) or L-aspartyl-L-phenylalanine methyl ester, a common artificial non-saccharide sweetener used as a sugar substitute in many foods and beverages, has shown some side effects on consumers. The objective of the present study is to study the acute impact of various doses of daily ingestion of APM on blood parameters of mice. Sixty healthy 3 months old male mice raised in the departmental animal house were divided into five groups i.e. the control were fed normal diet and tap water, while other 4 groups (12 each) were daily orally fed with $1 \mathrm{~mL}$ of either $40,500,1000$ or $1500 \mathrm{mg} / \mathrm{Kg}$ b wt, dissolved in distilled water using gavages for consecutive 5 weeks. Fresh blood samples collected directly from the heart at dissection were subjected to complete blood counting (CBC) using automated blood analyzer (Cell DYN-1700) in addition to manual differential Leucocytes (WBC) counting. There has been a significant increase $(p \leq 0.01)$ in WBC counts starting from the lowest dose $(40 \mathrm{mg} / \mathrm{Kg} \cdot \mathrm{b} \cdot \mathrm{wt})$; significant decrease $(p \leq 0.01)$ in both Hemoglobin percentages $(\mathrm{Hb} \%)$ and in Lymphocyte percentages $(p \leq 0.004)$ in comparison with control. It is concluded that the ingestion of aspartame using the above doses has acute impact and is not dose-dependent on blood parameters which could exert further, on the long run, health risks on to other tissues of consumers.
\end{abstract}

\section{Keywords}

Acute Effects, Aspartame, Blood Parameters, Mice, CBC

\section{Introduction}

Both the non-nutritive artificial di-peptide sweetener, aspartame (APM), and the natural nutritive are paid special attention among food additives as their use 
enables a sharp reduction in sugar consumption and a significant decrease in caloric intake meanwhile maintaining the desirable palatability of foods and soft drinks [1] [2]. Since the discovery of Aspartame in 1965, many studies carried out both on humans and animals showed a considerable controversy regarding its safety for human consumption including possible neurologic and behavioral side effects. Studies have shown that more than half of the populations prefer artificially sweetened food stuffs perhaps to avoid putting weight on [3]. Concerns relating to the possible adverse effects have been raised due to aspartame's metabolic components produced during its breakdown, namely phenylalanine (Phe), aspartic acid (aspartate), diketopiperazine (DKP) and methanol [4]. The APM, is produced commercially from the methyl ester of two amino acids: L-aspartic and L-phenylalanine methyl-ester which build the chemical structure of the aspartame [5]. The APM, nearly 200 times as sweet as sucrose with virtually no calories has since 1981 received approval for safe consumer use by the Food and Drug Administration (FDA) [6]. The American Dietetic Association [7] have numerous studies, in which they challenged the safety of APM consumption. The accepted daily recommended amount by the FDA is $50 \mathrm{mg} / \mathrm{Kg}$ body weight/day while the accepted or/and approved daily dose by the World Health Organization (WHO) is $40 \mathrm{mg} / \mathrm{kg} /$ day [8] [9]. Its main impurity, chemical and physical properties are detailed in other studies [10].

After entering the body, the components of aspartame are promptly released within the upper gastrointestinal tract (GIT) by enzymatic action. They then are transported across the wall of the small bowel and finally enter into the general circulation [11]. Methanol is hydrolyzed in the intestinal lumen with transport of the aspartylphenylalanine dipeptide into mucosal cells, where it is metabolized to aspartate and phenylalanine. Methanol accounts for approximately $10 \%$ of aspartame in terms of weight which is metabolized into formaldehyde, formic acid and $\mathrm{CO}_{2}$ which are then absorbed into the systemic circulation. Aspartame may also be absorbed by intestinal mucosal cells where it is hydrolyzed to its components, which are then absorbed into the systemic circulation [12]. Accordingly, the first tissue to be affected by these chemicals would be the blood. Further safety studies included acute bolus doses, repeated doses, administration in capsules to evaluate the appropriateness of capsules as a dosage form in blinded clinical studies, and aspartame ingested with meals. Long-term dosing safety studies have also been extensively reviewed [13]. However, there are supporters and opponents about credibility of aspartame's use. In human, aspartame ingestion for three days at a dose of $24-48 \mathrm{mg} /$ day showed that acute administration of aspartame has no influence on plasma glucose or insulin levels in diabetic rats and in patients with non-insulin-dependent diabetes mellitus [14]. While several researches involve various effects of aspartame from different prospects do exert relatively real risks on health; although contradicting, nevertheless, ASP is still in use. The hemostasis of the blood parameters can play an integral part in the normal functioning of any human being as well as animals. A wide variety of different animal models (mouse, rat, guinea pig, rabbits, pigs and monkeys) have 
already been tested to determine the effects of Aspartame influencing various tissues are comparable between animals and humans [15].

The research question was whether or not the morphology and number of the leukocytes could change following ingesting different doses of aspartame! The functions of the leukocytes of mice are similar to those of other mammals, including humans which all are investigated as complete blood counting [CBC] [16]. The CBC can be used by so many doctors as an indicator to check the body health at hospitals as well as by the scientists. The CBC, used to assess the effects of Diesel inhalation on Guinea pigs health was found to be a very useful and a practical tool [17].

The APM is widely used in the Mediterranean countries particularly amongst diabetics while its adverse effects is still in debate and there scanty studies to shed light on the acute impact of the APM on the health. Taking the accepted daily intake of aspartame, as approved by the FDA into account, the present study planned to distinguish the effects of aspartame at four doses, $40 \mathrm{mg} / \mathrm{kg}$, $500 \mathrm{mg} / \mathrm{kg}, 1000 \mathrm{mg} / \mathrm{Kg}$ and $1500 \mathrm{mg} / \mathrm{kg}$ aspartame body weight as short-term (acute) effects of aspartame ingestion on the complete blood counts as a tool for evaluation.

\section{Materials and Methods}

The APM was ordered commercially from Japanese Company, Tokyo Chemical Industry Co. (TCI) as a fine white powder of $25 \mathrm{gm}$ per bottle, with $98 \%$ purity percentage (CAS No. 22839-47-0) and the Synonyms N-L- $\alpha$-Aspartyl-Lphenylalanine1-Methyl Ester, $\mathrm{H}$-Asp-Phe-OMe and Chemical Formula of $\left[\mathrm{C}_{14} \mathrm{H}_{18} \mathrm{~N}_{2} \mathrm{O}_{5}\right]$. Four concentrations were prepared: 40, 500, 1000 and 1500 $\mathrm{mg} / \mathrm{Kg}$ body weight by dissolving in distilled water.

\subsection{Blood Analysis}

Blood sample of 2 - $3 \mathrm{~mL}$ per animal were collected in EDTA (ethylenediaminetetraacetic acid) contained ampoules and were shaken to avoid coagulation. They were analyzed both manually and/or mechanically using automated analyzer (Cell DYN-1700). Blood smears were prepared using fresh clean glass slides and stained with either Giemsa stain for differential counting using Olympus light microscopy.

\subsection{Complete Blood Counting (CBC)}

The blood samples were placed on a rack in the analyzer, a rotator machine called (RM5-Assistant 348) to mix blood well and to prevent blood coagulation prior analysis. The automated analysis machine was linked to both a screen monitor to show further details of the blood and to a printer. The cell counting component counts the numbers and types of different cells within the blood. In addition, the machine measures and analyzes red blood cells (RBC), white blood cells (WBC) and platelets (PLT) as well as amount of hemoglobin in the blood 
and within each red blood cell.

\subsection{Differential Counting of WBCs (Manually)}

The automated CBC machine had failed to differentially count the WBCs except the Lymphocytes which were predominant; however, a manual counting was carried out instead. A combined Wright-Giemsa stain (10 and 20 minutes respectively) was utilized for staining the blood smears [18]. The stained smears were then used for differential counting of leukocytes using oil immersion lens $(\times 100)$ by a drop of mustard oil. Counting was continued horizontally until a hundred leukocytes were distinguished. The number of zones was counted till a hundred leukocytes were distinguished.

\subsection{Experimental Protocol}

Sixty Swiss Webster adult healthy male mice aged 3 months have been raised at the "Departmental Animal House" were divided into five groups (G1-G5) each had around $20 \pm 2 \mathrm{gm} \mathrm{b}$ wt at the beginning of the experiments with all doses were calculated accurately and served accordingly. The first group was served as an untreated or control group (G1) while other four experimental groups (G2-G5) were treated with four doses: $40 \mathrm{mg} / \mathrm{kg}, 500 \mathrm{mg} / \mathrm{kg}, 1000 \mathrm{mg} / \mathrm{Kg}$ and $1500 \mathrm{mg} / \mathrm{kg}$ aspartame body weight. All animals were given an oral dose of the aspartame on daily basis (between $10-12 \mathrm{am}$ ) via gavages using stomach tube. These experiments were performed in accordance with standard animal welfare guideline and the Islamic legislation permission was obtained from the Ethnic Committee.

\subsection{Data Analysis}

Two ways ANOVA biostatistics program was used to analyze the data for comparison purposes against the control data and the significant differences were counted for probability test expressed as $p \leq 0.05$ or higher. Details are cited at table legends as appropriate.

\section{Results}

\subsection{Complete Blood Counting (CBC)}

The population of WBC had significantly increased $(p \leq 0.05)$ from $\left(6.025 \times 10^{3}\right.$ $\pm 486)$ in control to around $\left(9.35 \times 10^{3} \pm 223\right)$ in all 4 doses of Aspartame which stayed steady almost at higher doses (Table 1). While erythrocytes number had slightly dropped from $8.488 \times 10^{6} \pm 188 / \mu \mathrm{L}$ in control at the low dose to $8.32 \times$ $10^{6} \pm 188 / \mathrm{uL}$; however, they remained unchanged and stayed steady at higher doses around the whole experiments. The percentages of the hemoglobin $(\mathrm{Hg} \%)$ had significantly $(p \leq 0.02)$ dropped from $13.4 \% \pm 2.7 \%$ in control in comparison with that of the lowest dose $(12.2 \% \pm 1.8 \%)$ but remained almost steady at the higher. The records of platelets in 4 different doses of aspartame showed an insignificant decline in the number $\left(118 \pm 84\right.$ to $\left.112 \pm 117 \times 10^{3}\right)$. 
Table 1. The CBC of mice following ingestion of Aspartame. The biostatistics implied Student-T-stest ANOVA compared with the control. (n) = Number of animal used per experiment; Significant difference represented as $\left({ }^{*}\right) p \leq 0.012 ;\left({ }^{* *}\right) p \leq 0.019$ and $\left({ }^{* * *}\right) p$ $\leq 0.013$.

\begin{tabular}{|c|c|c|c|c|}
\hline $\begin{array}{c}\text { Standard } \\
\text { Number \& Units }\end{array}$ & $\begin{array}{c}\text { WBC } \\
\times 10^{3} / \mu \mathrm{L}\end{array}$ & $\begin{array}{c}\text { RBC } \\
\times 10^{6} / \mu \mathrm{L}\end{array}$ & $\begin{array}{l}\text { HGB } \\
\text { g/dl }\end{array}$ & $\begin{array}{c}\text { PLT } \\
\times 10^{6} \mathrm{~g} / \mathrm{dl}\end{array}$ \\
\hline Control \& $\pm S E$ & $\begin{array}{c}6.025 \pm 486 \\
n=8\end{array}$ & $\begin{array}{c}8.474 \pm 188 \\
n=8\end{array}$ & $\begin{array}{c}13.4 \pm 2.70 \\
\mathrm{n}=8\end{array}$ & $\begin{array}{c}1.187 \pm 84 \\
\mathrm{n}=8\end{array}$ \\
\hline $40 \mathrm{mg} / \mathrm{Kg}$ & $9.35 \pm 792^{\star}$ & $8.325 \pm 188$ & $12.3 \pm 382^{\star \star}$ & $1.095 \pm 78$ \\
\hline$\& \pm \mathrm{SE}$ & $\mathrm{n}=8$ & $\mathrm{n}=6$ & $\mathrm{n}=8$ & $\mathrm{n}=6$ \\
\hline $500 \mathrm{mg} / \mathrm{Kg}$ & $9.975 \pm 954^{*}$ & $8.403 \pm 99$ & $13.4 \pm 208^{\star *}$ & $1.087 \pm 56$ \\
\hline$\& \pm S E$ & $\mathrm{n}=8$ & $\mathrm{n}=8$ & $\mathrm{n}=8$ & $\mathrm{n}=7$ \\
\hline $1000 \mathrm{mg} / \mathrm{Kg}$ & $8.600 \pm 891^{*}$ & $8.464 \pm 110$ & $13.2 \pm 172^{\star *}$ & $1.086 \pm 66$ \\
\hline$\& \pm S E$ & $\mathrm{n}=7$ & $\mathrm{n}=9$ & $\mathrm{n}=8$ & $\mathrm{n}=6$ \\
\hline $1500 \mathrm{mg} / \mathrm{Kg}$ & $9.029 \pm 801^{\star}$ & $8.44 \pm 151$ & $12.9 \pm 189^{\star *}$ & $1.122 \pm 117$ \\
\hline$\& \pm S E$ & $\mathrm{n}=7$ & $\mathrm{n}=9$ & $\mathrm{n}=9$ & $\mathrm{n}=7$ \\
\hline
\end{tabular}

\subsection{Differential Counting and Morphology of WBCs}

The manual counting was carried out instead of automated and details are shown in Table 2. The differential counting of WBC in control mice was compatible to those of standard CBC of mice. Generally, the WBCs in mice are much smaller in size than other experimental animals i.e. rats and Guinea pigs. Lymphocytes, almost spherical, small cells ( $4.5 \pm 0.35$ um diameter) had sized slightly larger than RBC and could easily be identified. Some lymphocytes had semi-ovoidal or abnormal in treated mice and their percentage insignificantly fluctuated in the treated mice $(71 \%-63 \%)$.

Monocytes, were easily distinguishable as bean-shaped prominent nuclei within the cytoplasm. In some experimental mice, similar to lymphocytes, both their nuclei and the cytoplasm had tendency to stain darker than the normal ones. Their mean size raged $11 \pm 0.6$ um with transparent non-granulated cytoplasm around the nucleus. The cell membrane were clearly visible with larger surrounding cytoplasmic areas; however, some had lost cell membrane in experimental mice. Some showed vacuolated in both nuclei and cytoplasm leading to enlarged sizes. Their frequency had dropped down in the lower dose $(40 \mathrm{mg} / \mathrm{Kg}$ body weight) in comparison with the control (20.7\%) but fluctuated then after with the next three doses $(15 \%-23 \%)$ [Table 2].

The nuclei of the Neutrophils (segmented) in both control and aspartame treated mice stained brilliant blue with up to 8 lobes were well distinguishable. The size of the Netrophils of mice ranged (7.5 - $12.0 \mathrm{um}$ ) in diameter with a mean of $8.0 \pm 1.2 \mathrm{um}$ in comparison with other species. In experimental mice, occasionally, some showed vacculation inside the cytoplasm. The cell membranes in the control mice was more clearly visible than those of treated groups; however, in experimental mice, were seldom lost leaving nuclei lobes loose. Occasional Neutrophil-like small cells, with packed chromatin materials and slightly larger than lymphocytes were detectable in both control and treated 
Table 2. Differential counting of Leukocyte exposed to different doses of Aspartame as mean; percentage (\%) and \pm SE stained with both Wright and Giemsa stains is carried out using both automated machine and manually. Biostatistics is carried out using Student T-Test ANOVA compared with control. Significant difference represented as $\left(^{*}\right) p \leq$ $\left.0.012 ;{ }^{* *}\right) p \leq 0.019$ and $\left(^{* * *}\right) p \leq 0.013$.

\begin{tabular}{|c|c|c|c|c|c|}
\hline Standard & LYM & Mono & Neutrophils & Basophils & Eosinophils \\
\hline Number \& Units & $\%$ & $\%$ & $\%$ & $\%$ & $\%$ \\
\hline $\begin{array}{c}\text { Control \& } \pm \text { SE } \\
n=8\end{array}$ & $74 \pm 2.37$ & $20.67 \pm 2.4$ & $5.33 \pm 1.0$ & 0 & 0 \\
\hline \multicolumn{6}{|l|}{$40 \mathrm{mg} / \mathrm{Kg}$} \\
\hline $\begin{array}{c}\& \pm S E \\
n=8\end{array}$ & $71.0 \pm 2.5$ & $15.00 \pm 1.9$ & $6.33 \pm 2.09^{* * *}$ & $2.33 \pm 0.5$ & $5.33 \pm 1.2$ \\
\hline \multicolumn{6}{|l|}{$500 \mathrm{mg} / \mathrm{Kg}$} \\
\hline $\begin{array}{c}\& \pm S E \\
n=8\end{array}$ & $74.50 \pm 2.2$ & $23.17 \pm 1.9$ & $7.83 \pm 0.5^{\star * \star}$ & $0.33 \pm 0.2$ & $0.50 \pm 0.2$ \\
\hline \multicolumn{6}{|l|}{$1000 \mathrm{mg} / \mathrm{Kg}$} \\
\hline $\begin{array}{c}\& \pm S E \\
n=8\end{array}$ & $80.5 \pm 2.2$ & $10.33 \pm 1.6$ & $6.17 \pm 1.3^{* * *}$ & $1.00 \pm 0.5$ & $1.83 \pm 0.5$ \\
\hline \multicolumn{6}{|l|}{$1500 \mathrm{mg} / \mathrm{Kg}$} \\
\hline $\begin{array}{c}\& \pm \mathrm{SE} \\
\mathrm{n}=8\end{array}$ & $63.33 \pm 1.0$ & $22.00 \pm 1.0$ & $9.67 \pm 1.5^{\star * \star}$ & $3.33 \pm 0.4$ & $0.5 \pm 0.2$ \\
\hline
\end{tabular}

group mice. These small cells had caused some confusion in differential counting of WBC in verifying between Neutrophils and lymphocytes.

Both Basophils and Eosinophils in mice blood were so rare and could hardly be recognized in comparison with human and other higher mammals. They had slightly bigger size than the Neutrophils (10.2 \pm 1.5 um in diameter). Verification of these two leukocyte types was not easy task to differentiate in both control and aspartame treated mice. Occasionally, some small, slightly bigger than the Lymphocytes $(7.5 \pm 1.0 \mathrm{um})$, perhaps, were detectable from their bi-lobed nuclei with only difference in the colour of cytoplasm. These cells were considered as either small Basophils or Eosinophils relevant to the color (blue or right, respectively) of the cytoplasmic granules. The percentages of both Basophils and the Eosinophils scored 0\% - 5\% which were fluctuating but within the standard ranges of mice. Blood platelets, on the other hand, showed no significant changes although were easily detectable in all blood smears. Their counts were around the standard records of the mice.

\section{Discussion}

All mice encountered in these experiments were from the same batch, healthy males and same age to guarantee an unbiased interpretation of the results. The protocol and the technique of oral administration of aspartame approved to be successful throughout the 5 weeks experiments due to no mortality incidents. The survival of the experimental animals throughout 5 weeks experiments implied all doses used (40 - $1500 \mathrm{mg} / \mathrm{Kg} \cdot \mathrm{b} \cdot \mathrm{wt}$.) may indicate the none-lethality of the aspartame. However, animals received the highest doses of Aspartame (1500 $\mathrm{mg} / \mathrm{Kg} \cdot \mathrm{b} \cdot \mathrm{wt}$.) had seriously injured themselves at the back parts of the body towards the end of week 5 indicating development of aggressive behavior. While a 
specific reason for such aggression is unclear at this stage the only interpretation could therefore, be attributed to an accumulative effects of this dose might have provoked raise the blood pressure or/and induced an increase in adrenal gland activity leading to secretion of cortisone which is in concomitant with an earlier study [19]. The actual etiology of such aggressiveness could be further explored via biochemical-behavioral studies which is beyond the scope of this research.

Since 1965 many studies conducted worldwide to approve its safety are still conflicting leading to two different opposing schools where one with safety consumption of the APM while another against. However, the latter is governed by two main factors i.e. the various scenarios in which these researches are conducted and the commercial greed by the manufactures who make a fortune every year. Nevertheless, it has been announced safe and recommended by doctors to the diabetics at every part of the world. It is almost an impossible deal nowadays to follow a diet completely free of sweeteners and/or other additives [1]. From industrial purposes, additives have become inevitably a must to extend shelf life and to improve flavour, colour and texture or sweeten food which include antioxidants, preservatives, stabilizers, colorants, flavours, emulsifiers and sweeteners [20]. Fortunately, APM is mostly used in uncooked foods as the cooking, otherwise any elevation in temperature or extremes of $p \mathrm{H}$, have shown changes in the chemical structure and composition of its three components leading changes in their consequent effects via converting the esterified di-peptide, non-enzymatically into a variety of decomposed products [21]. The risk to the health, therefore, generates from metabolites of the APM in the upper GIT into the amino acids aspartic acid (Asp), phenylalanine (Phe) and methanol which will be absorbed and hydrolyzed to its components, transported across the wall of the small bowel and finally into the general systemic circulation [22]. The Asp is mostly eliminated through the lungs in the form of $\mathrm{CO}_{2}$ and some of the Phe formed is excreted in the form of $\mathrm{CO}_{2}$ too where most of it is incorporated into the pool of amino acids and contributes to protein synthesis. Therefore, the first line of impact to the health of these metabolites will imply the blood parameters which could be detected by the $\mathrm{CBC}$ test. Accordingly, health condition, could well be assessed by the deviation of its parameters than the normal.

Earlier studies on seven infant monkeys given APM with milk showed that the high dose group did not consume the intended levels of APM leading to conclusion that the high-dose group actually ingested approximately as much APM as the medium-dose group [23]. Luckily, this may indicate that the body has the capacity to absorb a certain limit of APM dose while higher doses may be discharged in certain way off the body or/and render, harmless.

The general records of blood parameters in this research are similar to the standard records documented in other references indicating both reliability and accuracy of the CBC counting of this work. The various haematological disorders manifested in this work ranged between none-significant to highly significant. The actual effects of APM on blood which circulates the nutrition and oxygen to all body tissues would therefore be feasible to consider throughout the 
changes of its components. Some haematological disorders have been attributed to the prevention of $\mathrm{RBC}$ synthesis via inhibition of erythropoeisis in the bone marrow with the resultant development of anemia [24].

The sizes of WBCs of mice, in general, are much smaller than other laboratory animals i.e. rats, Guinea pigs and rabbits [17] [25]. Their sizes seem to be proportional, to certain extend, with the size of animals. Such small size of mice might have, inevitably, confused the automated analyzing machine in differentiating the leucocytes while accidental mistakes at manual counting might be undeniable.

The total frequency of WBC had significantly increased in all four doses of APM before settling almost, at higher doses. Their frequency in the blood are often indicative to diseases [26] [27] while elevation is considered to be a sharp indication of the state of immune system in response to any foreign invader into the body [28] [29]. Elevation in total number of WBC can often occur due to various microbial infections, cancer, or drug intake; however, "leucocytosis" after eating a large meal or experiencing stresses has also been detected [30] [31]. Thus the elevation of WBC in the experimental mice might be due to recognition of the APM metabolites by the immune system as foreign bodies.

The mean percentage of lymphocyte was within the standard limits of mice indicating no effects of APM doses on lymphocyte populations. Accordingly, it is unlikely to relate any blood disorder i.e. lymphobia due to the action of APM on blood. This result is on contrary to other studies on human of which both attributed it to a possible development of leukemia (lymphobia) [4] [32].

The variations in size of Monocytes could have caused a little confusion in the differential counting leading to some unexpected numerical error. A few Monocyte appeared with extra dense spherical bodies inside the cytoplasm denoting a new type of Monocytes specific to mice. This type of WBCs is similar to Foa Karloff cells being described for Guinea pigs and rabbits [25] and Guinea pigs [17]. It might not, therefore, be wrong to assume the equivalency of these leucocytes in mice to Fao Karloff cells of Guinea pigs and rabbits. The nuclei of Monocytes appeared with both darker and lighter which is not described in previous works involved the mice blood. Some Monocytes had developed vacuoles in their cytoplasm as well as in the nucleus and/or lost the cellular membranes while others had amorphous particularly at higher dose of APM in comparison with the control animals. This is a clear sign of APM action on this type of WBCs in all doses being used indicating their susceptibility to APM than other types. Such changes have already been explored by a cytological study using TEM (Unpublished data).

There are many possible interpretations for an abnormal raise in Neutrophil count at the highest dose e.g. more than 8000 is considered to be abnormally high i.e. a high level of stress; sudden infection from bacteria, burn injuries and a heart attack; sudden kidney failure, eclampsia, cancer spreading in the body [33]. The significant increase in the proportion of Neutrophils in this study could only be attributed to the provoked immune system which was triggered by the 
higher dose to recruit the Neutrophils as an immediate response to the toxic effects of the APM. This might interpret the increase in small Neutrophils (band or B-Neutrophils) which do elevate in case of infection by foreign chemicals [34].

No effect on erythrocytes (RBC) number in all doses of treated bloods in comparison with control was recorded in this study. This result is in concomitant with other studies which showed a little effects of APM and glutamate on RBC concentration nor to plasma following ingestion of APM plus Monosodium L-glutamate in human [35] [36] while low doses exerted no harm to membrane enzyme activity, but high dose did [37]. However, such a promising outcome indicates the fact that the administration of lower doses of APM may be safer than higher doses. In this research the activity of membrane enzyme was not measured as it is out of scope of the protocol.

The APM treated mice revealed a significant decline in hemoglobin percentages which clinically refers to blood disorder e.g. destruction of RBC [hemolysis] leading to anemia [28] [38]. The drop in $\mathrm{Hb} \%$ might therefore be attributed to the effects of APM metabolites i.e. methanol which breaks down the protein bond of haemoglobin [39]. Such a drop in $\mathrm{Hb} \%$ does raise some clinical questions to be further addressed by hematologists regarding the mechanism of action of APM on blood components and its consequence. This study involved the short-term of low and high dose effects of APM on blood mice. Therefore, the current results may indicate the early effects of the APM on some blood parameter while further harms on other blood components may be expected on the long-term.

\section{Conclusion}

It is concluded the impact of APM, has acute, direct and various side effects on blood components which seem to be non-dose dependant but could indicate health risk on the long run depending on a few factors. Perhaps further experiments i.e. long-term experiments are required to study the destructive effects of APM on these two vital tissues in the body.

\section{Acknowledgements}

This research has been approved by the Scientific Council of the Faculty of Science for MSc project for Mrs Norah S. Urwi Aljohany which implies the ethical committee approval to carry out scientific experiments on experimental animals.

\section{Conflicts of Interest}

The authors declare no conflicts of interest regarding the publication of this paper.

\section{References}

[1] Vences-Mejia, A., Labra-Ruiz, N., Hernandez-Martinez, N., Dorado-Gonzalez, V., 
Gomez-Garduno, J., Perez-Lopez, I., Nosti-Palacios, R., Carranza, R.C. and Espinosa-Aguirre, J.J. (2006) The Effect of Aspartame on Rat Brain Xenobiotic-Metabolizing Enzymes. Human Experimental Toxicology, 25, 453-459. https://doi.org/10.1191/0960327106het646oa

[2] Azad, M.B., Abou-Setta, A.M., Chauhan, B.F., Rabbani, R., Lys, J., Copstein, L, Mann, A., Jeyaraman, M.M.; Reid, A.E., Fiander, M., MacKay, D.S., McGavock, J., Wicklow, B. and Zarychanski, R. (2017) Nonnutritive Sweeteners and Cardiometabolic Health: A Systematic Review and Meta-Analysis of Randomized Controlled Trials and Prospective Cohort Studies. CMAJ, 189, E929-E939. https://doi.org/10.1503/cmaj.161390

[3] Santos, N.C., de Araujo, L.M., De Luca Canto, G., Guerra, E.N., Coelho, M.S. and Borin, M.F. (2017) Metabolic Effects of Aspartame in Adulthood: A Systematic Review and Meta-Analysis of Randomized Clinical Trials. Critical Reviews in Food Science and Nutrition, 1-14.

[4] Trocho, C., Pardo, R., Rafecas, I., Virgili, J., Remesar, X., Fernandez-Lopez, J.A. and Alemany, M. (1998) Formaldehyde Derived from Dietary Aspartame Binds to Tissue Components in Vivo. Life Science, 63, 337-349. https://doi.org/10.1016/S0024-3205(98)00282-3

[5] Wardlaw, G.M. and Kessel, M.W. (2002) Carbohydrates: In: Perspectives, In: Nutrition, 5th Edition, McGraw Hill, Boston, New York, London, 189.

[6] Coulombe, R.A. and Sharma, R.P. (1986) Neurobiochemical Alterations Induced by the Artificial Sweetener Aspartame (Nutrasweet). Toxicology and Applied. Pharmacology, 83, 79-85. https://doi.org/10.1016/0041-008X(86)90324-8

[7] American Dietetic Association (ADA) (1998) Use of Nutritive and Non Nutritive Sweeteners. Journal of the American Dietetic Association, 98, 580-587.

[8] Leon, A.S., Hunninghake, D.B., Rassin, D.K. and Telphy, T.R. (1989) Safety of Long Term Large Doses of Aspartame. JAMA Internal Medicine, 149, 2318-2324. https://doi.org/10.1001/archinte.1989.00390100120026

[9] Butchko, H.H., Stargel, W.W., Comer, C.P., Mayhew, D.A., Benninger, C. and Blackburn, G.L. (2002) Aspartame: Review of Safety. Regulatory Toxicology and Pharmacology, 35, S1-S93. https://doi.org/10.1006/rtph.2002.1542

[10] Magnuson, B.A., Burdock, G.A., Doull, J., Kroes, R.M., Marsh, G.M., Pariza, M.W., Spencer, P.S., Waddell, W.J., Walker, R. and Williams, G.M. (2007) Aspartame: A Safety Evaluation Based on Current Use Levels, Regulations, and Toxicological and Epidemiological Studies. Critical Reviews in Toxicology, 37, 629-727. https://doi.org/10.1080/10408440701516184

[11] Roberts, H.J. (2011) Books and Recordings. Frank Ray Rifkin Publisher, Nutrition Health Review. http://www.sunsentpress.com/

[12] Stegink, L.D. (1987) The Aspartame Story: A Model for the Clinical Testing of a Food Additive. The American Journal of Clinical Nutrition, 46, 204-215. https://doi.org/10.1093/ajcn/46.1.204

[13] Kirkland, D. and Gatehouse, D. (2015) Aspartame: A Review of Genotoxicity Data. Food and Chemical Toxicology, 84, 161-168. https://doi.org/10.1016/j.fct.2015.08.021

[14] Shigeta, H., Yoshida, T., Nakai, M., Mori, H., Kano, Y. and Nishioka, H. (1985) Effects of Aspartame on Diabetic Rats and Diabetic Patients. Journal of Nutritional Science and Vitaminology (Tokyo), 31, 533-540. https://doi.org/10.3177/jnsv.31.533

[15] Pretorius, R.G., Bao, Y.P., Belinson, J.L., Burchette, R.J., Smith, J.S. and Qiao, Y.L. 
(2007) Inappropriate Gold Standard Bias in Cervical Cancer Screening Studies. International Journal of Cancer, 121, 2218-2224. https://doi.org/10.1002/ijc.22991

[16] Lester, V.K., Tarpley, H.L. and Latimer, K.S. (2007) Small Mammal Hematology: Leukocyte Identification in Rabbits and Guinea Pigs. Veterinary Clinic Pathology Clerkship Program, 1-8.

[17] Bazzaz, A.A. and Almanea, N.N. (2012) Assessment of the Acute Effects of Diesel Exhaust Emitted (DEE) on Blood Parameters of Guinea Pigs (Cavia porcellus). Journal of Environmental Sciences and Engineering, 5, 629-636.

[18] Humason, L.G. (1967) Animal Tissue Techniques Animal Tissue Techniques. W.H. Freeman and Company Stock, San Francisco.

[19] Abdullah, I.Z.A. (2002) Physiological Changes Induced by Long Term Administration of Saccharin Compared with Aspartame to Male Albino Rats. Egyptian Journal of Hospital Medicine, 8, 70-81.

[20] Duyff, R.L. (2002) American Dietetic Association Complete Food and Nutrition Guide. 2nd Edition, John Wiley \& Sons, Hoboken, No. 127, 194-198.

[21] Lipton, R.B., Newman, L.C., Cohen, J.S. and Solomon, S. (1998) Aspartame as a Dietary Trigger of Headache. Headache, 29, 90-92. https://doi.org/10.1111/j.1526-4610.1989.hed2902090.x

[22] Burgert, S.L., Anderson, D.W., Stegink, L.D., Takeuchi, H. and Schedl, H.P. (1991) Metabolism of Aspartame and Its L-Phenylalanine Methyl Ester Decomposition Product by the Porcine Gut. Metabolism, 40, 612-618. https://doi.org/10.1016/0026-0495(91)90052-X

[23] Stoddard, M.N. (1995) The Deadly Deception. Compiled by the Aspartame Consumer Safety Network for Volumes of Available Published Information. ACSN, Dallas.

[24] Neu, N., Wenby, R. and Meiselman, H.J. (2008) Effects of Dextran Molecular Weight on Red Blood Cell Aggregation. Biophysical Journal, 95, 3059-3065. https://doi.org/10.1529/biophysj.108.130328

[25] Percy, D.H. and Barthold, S.W. (2001) Pathology of Laboratory Rodents and Rabbits. Wiley \& Sons, Hoboken.

https://www.abebooks.co.uk/book-search/title/pathology-laboratory-rodents-rabbit s/author/percy-dean-barthold-stephen/

[26] Alberts, B. (2005) Leukocyte Functions and Percentage Breakdown. Molecular Biology of the Cell. NCBI Bookshelf.

[27] Hyeon-Kyoung, K., Hyung, K.K., Song, P., Hye Kyeong, P., Sung-Soon, L. and Hoon, J. (2017) Systemic White Blood Cell Count as a Biomarker Associated with Severity of Chronic Obstructive Lung Disease. Tuberculosis and Respiratory Diseases, 80, 304-310. https://doi.org/10.4046/trd.2017.80.3.304

[28] Mischer, A.L. (2010) Junqueira's Basic Histology. Text \& Atlas. 12th Edition, McGraw Hill Companies, New York.

[29] Gurney, J.G., Pogoda, J.M., Holly, E.A., Hecht, S.S. and Preston-Martin, S. (1997) Aspartame Consumption in Relation to Childhood Brain Tumor Risk: Results from a Case-Control Study. Journal of the National Cancer Institute, 89, 1072-1074. https://doi.org/10.1093/jnci/89.14.1072

[30] Hoefs, J.C. (2006) Increase in Ascites White Blood Cells and Protein Concentration during Dieresis in Patient with Chronic Liver Disease. Hepatology, 1, 249-254. https://doi.org/10.1002/hep.1840010310

[31] Rogers, K. (2011) Leukocytosis Definition. Blood: Physiology and Circulation. Bri- 
tannica Educational Publishing, Chicago, 198.

[32] Mitchell, H. (2006) Sweeteners and Sugar Alternatives in Food Technology. Wiley-Blackwell, Oxford, UK, 94.

[33] Keith T.A. (1977) Hypertension Crisis. Recognition and Management. JAMA, 237, 1570-1577. https://doi.org/10.1001/jama.1977.03270420038013

[34] Kurdi, K.N. (2012) Comparative Study of the Air Pollutants on Blood Parameters of Three Types of Animals at Quba Street, in Al-Madinah Al-Munawara. MSc Thesis, Taibah University, Taibah.

[35] Stegink, L.D., Filer, L.J. and Baker, G.L. (1977) Effect of Aspartame and Aspartate Loading upon Plasma and Erythrocyte Free Amino Acid Levels in Normal Adult Volunteers. The Journal of Nutrition, 107, 1837-1845. https://doi.org/10.1093/jn/107.10.1837

[36] Stegink, L.D., Filer, L.J. and Baker, G.L. (1982) Effect of Aspartame plus Monosodium L-Glutamate Ingestion on Plasma and Erythrocyte Amino Acid Levels in Normal Adult Subjects Fed a High Protein Meal. The American Journal of Clinical Nutrition, 36, 1145-1152. https://doi.org/10.1093/ajcn/36.6.1145

[37] Tsakiris, S., Giannoulia-Karantana, A., Simintzi, I. and Schulpis, K. (2006) The Effect of Aspartame Metabolites on Human Erythrocyte Membrane Acetylcholinesterase Activity. Pharmacological Research, 53, 1-5. https://doi.org/10.1016/j.phrs.2005.07.006

[38] Maton, A., Hopkins, J., McLaughlin, C.W., Johnson, S., Warner, M.Q., LaHart, D. and Wright, J.D. (1993) Human Biology and Health. Prentice Hall, Englewood Cliffs.

[39] Jun, C., Xue, Y., Liu, R. and Wang, M. (2011) Study on the Toxic Interaction of Methanol, Ethanol and Propanol against the Bovine Hemoglobin (BHb) on Molecular Level. Spectrochimica Acta Part A: Molecular and Biomolecular Spectroscopy, 79, 1406-1410. https://doi.org/10.1016/j.saa.2011.04.076 